\title{
A promoção da acessibilidade linguística ao docente surdo na UFG/Regional Catalão
}

\section{Promotion of language accessibility to the professor with deafness at UFG/Regional Catalão}

\section{DOI: $\underline{\text { http://dx.doi.org/10.5965/198431781642020293 }}$}

Kássia Mariano de Souza

Universidade Federal de Goiás

kassiamariana2008@hotmail.com

Maria Helena de Paula

Universidade Federal de Goiás mhp.ufgcatalao@gmail.com

\section{RESUMO}

O objetivo deste artigo é analisar como a Universidade se posiciona frente aos desafios legais para a implementação da acessibilidade linguística aos docentes surdos, principalmente no que tange à contratação do profissional intérprete como meio de inclusão do professor no contexto acadêmico. Assim, buscamos analisar as políticas públicas voltadas à acessibilidade deste profissional, tendo em vista que é recorrente sua inserção nas salas de aula e, sobretudo, nas universidades. O objeto de pesquisa desse trabalho é discutir sobre a promoção da acessibilidade linguística ao docente surdo na UFG/Regional Catalão, onde há uma atuação frequente de educadores com surdez. A fundamentação teórica do estudo se valeu das obras de autores que atuam na área da inclusão e acessibilidade da pessoa surda como Schubert (2012) e Quadros (2004; 2005). Realizamos ainda uma pesquisa documental sobre as medidas tomadas para tornar o ambiente acadêmico mais acessível a esses profissionais na instituição. Além disso, analisamos a legislação que abrange assuntos concernentes à acessibilidade que legalmente deve ser oferecida às pessoas surdas como suporte para correlacionar às informações obtidas. A pesquisa revelou que a Universidade ainda não está preparada para incluir o profissional surdo como parte constituinte da instituição.

Palavras-chave: Docente; Surdez; Acessibilidade;

\section{ABSTRACT}

The aim of this paper is to analyze how the University is positioned in front of the legal challenges for the implementation of the linguistic accessibility to deaf teachers, especially regarding the hiring of the professional interpreter as a means of inclusion of the teacher in the academic context. Thus, we seek to analyze the public policies aimed at the accessibility of this professional, since it is recurrent its insertion in the classrooms and, above all, in the universities. The purpose of this research is to discuss the promotion of linguistic accessibility to the deaf teacher at the UFG / RC. The theoretical basis of the study was based on the works of authors who work in the area of inclusion and accessibility of deaf people such as Schubert (2012), Quadros (2004; 2005). We also conducted a documentary research on the measures taken to make the academic environment more accessible to these professionals 
in the institution. In addition, we analyze the legislation that covers matters concerning the accessibility that should be legally offered to deaf people as a support to correlate the information obtained. The research revealed that the University is not yet ready to include the deaf professional.

Keywords: Teacher. Deafness. Accessibility.

\section{Introdução}

A trajetória do surdo é marcada, desde a Antiguidade, por lutas constantes no sentido de legitimar seus direitos. Mais recentemente esses direitos foram garantidos pela legislação nacional (Lei n 10.436/2002 e Decreto n 5.626/2005) e, com a legitimação do direito, houve um crescimento significativo nas pesquisas voltadas para as análises das políticas de inclusão do aluno surdo na rede regular de ensino.

Apesar da projeção social do sujeito surdo e, consequentemente, sua inserção no meio acadêmico, não apenas como discente, mas, sobretudo, como profissional docente, essa temática ainda não foi objeto de muitas pesquisas. Assim, faz-se necessário analisar a seguinte questão: como se configura no cenário acadêmico da Universidade Federal de Goiás/ Regional Catalão, a acessibilidade voltada ao docente surdo, especialmente no que diz respeito à acessibilidade linguística?

Portanto, a pesquisa que ora propomos visa discutir e entender o que Borges; Valenzuela e Carneiro (2013, p. 03) chamam de "inclusão contrária", ou seja, neste caso, não é o aluno quem necessita da inclusão na sala de aula, mas o professor. A proposta deste estudo é, portanto analisar se há e, de que maneira a acessibilidade está sendo garantida ao educador surdo que atua no nível superior de ensino.

As análises são realizadas com base na inserção do docente surdo no quadro de profissionais da UFG/RC, tendo em vista que, na referida Regional, trabalharam/ trabalham três docentes surdos, sendo dois deles contratados como professores substitutos e um aprovado em concurso efetivo.

Assim, procuramos compreender se a Universidade oferece amparo a esses profissionais quanto à eliminação das barreiras de comunicação com o grupo 
acadêmico em geral, não somente na relação professor surdo e alunos ouvintes, mas também no convívio com os demais professores e colegas de trabalho. Para a obtenção de respostas a tal questionamento, foi analisada a documentação referente à contratação desses profissionais e observadas quais medidas foram tomadas pela universidade a fim de garantir acessibilidade aos docentes.

A pesquisa intentou esclarecer ainda, como a UFG/RC se posiciona frente aos desafios legais necessários para a implementação de acessibilidade linguística a estes profissionais, principalmente no que tange à contratação do profissional intérprete como meio de inclusão do docente no contexto acadêmico.

Quadros (2004 e 2005) afirma que a presença do intérprete se configura como um dos elementos centrais no que diz respeito à acessibilidade do surdo, por isso há a necessidade de investigar se esse elemento crucial está sendo, de fato, integrado no cotidiano do docente surdo.

Enfatizamos, ainda, que, de acordo com o Decreto $n^{\circ}$ 5.626/05 (BRASIL, 2005), no parágrafo único do Art. 4, a Língua Brasileira de Sinais (Libras) deve ser ensinada preferencialmente por pessoas surdas, uma vez que, por meio delas, os alunos poderão compreender de maneira mais significativa aspectos sobre a língua e a cultura surda. Apesar dos surdos terem essa prioridade, é necessário averiguar se as instituições estão preparadas para receber e lidar com esse profissional surdo.

Diante do exposto, para obtermos as informações pertinentes à contratação dos docentes surdos, recorremos ao Departamento Pessoal (DP) da Regional mencionada para tomarmos conhecimento da documentação e de outras informações pertinentes. Solicitamos também no Departamento de Desenvolvimento de Recursos Humanos (DDRH) as informações e documentação que comprovam as medidas que foram tomadas para tornar a universidade mais acessível aos docentes surdos. Ambas as solicitações foram respondidas na forma de memorando expedido pelos departamentos supracitados.

Assim, analisamos os memorandos com o objetivo de verificar se foram tomadas iniciativas e quais foram. Buscamos informações acerca da contratação do 
profissional intérprete, bem como se houve a difusão da Língua Brasileira de Sinais por meio de cursos ofertados aos demais profissionais da comunidade acadêmica.

Conforme citado anteriormente, as pesquisas voltadas à acessibilidade do docente com surdez ainda são escassas, por isso a fundamentação teórica da pesquisa se valerá basicamente dos trabalhos concernentes à cultura surda, como discutida por Strobel (2008); à identidade surda, debatida por Perlin; Miranda (2003) e às discussões das pesquisas relacionadas ao intérprete de Libras, como em Quadros (2004) e Schubert (2012; 2015).

Utilizamos também a legislação nacional que nos serviu de apoio para que as informações coletadas fossem relacionadas à legislação vigente. Dessa forma, nos serviram de base a lei $n^{0} 10.436$ de 24 de Abril de 2002, que reconhece a Língua Brasileira de Sinais como língua oficial dos surdos; o decreto 5.626/2005 que regulamenta a lei $n^{\circ} 10.436 / 2002$ e assegura os direitos da pessoa surda por meio da formação e inserção do intérprete de Língua de Sinais; a lei no $10.098 / 2000$, que estabelece normas gerais e critérios básicos para a promoção da acessibilidade das pessoas portadoras de deficiência e, por fim, a lei $n^{\circ}$ 12.319/2010, que regulamenta a profissão de Intérprete e garante a este profissional a valorização necessária para o exercício de sua função.

Para discutir melhor o tema aqui apresentado, dividimos o trabalho em quatro seções. Na primeira delas, fizemos um apanhado histórico da luta e conquistas da comunidade surda no Brasil, nos últimos dez anos. Na segunda situamos o leitor acerca da inserção dos docentes surdos no meio acadêmico, bem como a apresentação das leis que os amparam enquanto profissionais qualificados para transmitirem o saber. Na terceira, pontuamos a importância do profissional intérprete como meio legal de acessibilidade às pessoas surdas; na quarta nos dedicaremos à análise da documentação referente à contratação dos professores surdos e às medidas tomadas pela UFG/RC no intuito de garantir a acessibilidade a esses profissionais. Por fim, nas considerações finais, apresentamos um resumo dos resultados obtidos por meio da pesquisa. 


\section{Lutas e conquistas da comunidade surda no Brasil}

Historicamente, os surdos foram considerados inferiores à sociedade de ouvintes devido ao fato de estarem desprovidos da característica primordial do homem: a linguagem oral. A comunicação das pessoas limitadas quanto à audição era realizada por meio de sinais, porém estes eram vistos pela sociedade como mímicas e gestos que não possuíam qualquer fundamento. Até mesmo suas capacidades intelectuais eram questionadas pelo fato de não se comunicarem como as pessoas ouvintes, isto é, pelo canal oral-auditivo, mas de maneira visual-gestual. De acordo com Monteiro (2006), em décadas passadas, o uso de sinais era banalizado principalmente pelos familiares de pessoas surdas, uma vez que os sinais eram motivo de vergonha e, por isso, na maioria das vezes, preferiam escondê-los da sociedade. Tudo isso contribuiu para a existência do processo de hegemonia entre as pessoas ouvintes sobre as pessoas com surdez.

Foi por isso, que, com o passar dos anos, a comunidade surda percebeu a necessidade de lutar pelo reconhecimento de sua cultura e, sobretudo, de sua identidade para que sua cidadania passasse a ser respeitada. É necessário pontuarmos que, de acordo com Strobel (2008), comunidade surda não diz respeito apenas às pessoas surdas, mas a todos que militam pela causa surda, como pais, professores e intérpretes. Dessa forma, um dos marcos dessa comunidade foi alcançado no ano de 2000, por meio da promulgação da lei $n^{\circ} 10.098$ de 19 de Dezembro. Esta lei versa sobre as normas gerais e critérios básicos para a promoção da acessibilidade das pessoas com deficiência e, de acordo com o artigo 17 do capítulo VII,

O Poder Público promoverá a eliminação de barreiras na comunicação e estabelecerá mecanismos e alternativas técnicas que tornem acessíveis os sistemas de comunicação e sinalização às pessoas portadoras de deficiência sensorial e com dificuldade de comunicação, para garantir-lhes o direito de acesso à informação, à comunicação, ao trabalho, à educação, ao transporte, à cultura, ao esporte e ao lazer (BRASIL, 2000). 
Apesar de estar previsto o acesso à comunicação, a comunidade surda continuou buscando pelo reconhecimento da língua de sinais e das pessoas surdas perante a sociedade de ouvintes. Por isso, intensifica-se o movimento surdo que, atualmente, está representado no Brasil pela Federação Nacional de Educação e Integração de Surdos (Feneis) ${ }^{1}$, cujo objetivo é fomentar as discussões a fim de potencializar a pessoa surda. Monteiro (2006) pontua a intensificação dos debates que visam à inclusão e melhor qualidade de vida da pessoa surda, hoje representada no Brasil por uma (1) Confederação, oito (8) Federações e noventa e cinco (95) Associações de Surdos espalhadas pelos estados.

No Brasil, a década de 1990 foi marcada fortemente pelos movimentos surdos que objetivavam o reconhecimento da Língua Brasileira de Sinais (Libras), como primeira língua das pessoas surdas. "Várias mobilizações, como passeatas, atos públicos em parlamentos e nas ruas, articuladas por associações e escolas de surdos marcavam os calendários das escolas e entidades representativas de surdos, familiares e educadores" (THOMA; KLEIN, 2010, p. 26). Esses movimentos resultaram primeiramente no reconhecimento da Libras como língua oficial em alguns estados como Minas Gerais, Santa Catarina e Rio Grande do Sul. Porém, a comunidade surda não desistiu e continuou lutando até a chegada dessa proposta ao Congresso Nacional no ano de 2002, quando foi promulgada a lei $n^{\circ} 10.436 / 2002$ que reconheceu a língua de sinais em todo território nacional.

Dessa forma, a luta pela legitimação da língua de sinais se caracterizou como uma das conquistas mais importantes na trajetória de lutas das pessoas surdas. Podemos afirmar que a lei $n^{\circ} 10.436 / 2002$ veio legitimar não apenas a língua, mas as pessoas surdas que passaram a ter seu meio de expressão reconhecido pela sociedade e, o mais importante, os sinais deixaram de ser vistos como mímica, sendo reconhecidos como sinais, que para Souza e Novodvorski (2019) trata-se do conjunto de vocábulos que dão origem ao léxico da Libras.

\footnotetext{
${ }^{1}$ A Feneis é uma entidade filantrópica, sem fins lucrativos, que tem por finalidade a defesa de políticas em educação, cultura, saúde e assistência social, em favor da comunidade surda brasileira, bem como a defesa de seus direitos.
} 
A importância da língua de sinais para a comunidade surda é compreendida por Strobel (2008) como:

[...] uma das principais marcas da identidade de um povo surdo, é uma das peculiaridades da cultura surda, é a forma de comunicação que capta as experiências visuais dos sujeitos surdos, sendo que esta é a língua que vai levar o surdo a transmitir e proporcionar-lhe a aquisição de conhecimento universal (STROBEL, 2008, p. 44).

A identidade, que é fortemente caracterizada pela cultura e pela língua de uma pessoa ou de um grupo, no caso dos surdos, língua de sinais ganha uma importância ímpar por inseri-los na cultura e dar-Ihes um pertencimento a um grupo, no qual se reconhece, com o qual se interagem e do qual participa.

Além disso, é através dela que os surdos são inseridos na sociedade de ouvintes e se projetam socialmente. Nesse mesmo sentido, citamos Schubert (2015), quando pondera que a língua de sinais é, para o surdo, a principal maneira de manifestar sua cultura, valores e identidade e o desejo de que esta seja legitimada e desenvolvida é uma luta histórica da comunidade surda.

Essa lei veio ao encontro dos anseios dos movimentos surdos no sentido de que sua língua fosse legitimada, e ainda ampliou as oportunidades dessas pessoas que, desde então, se viram mais motivadas a continuarem lutando por seus direitos. O reconhecimento da língua de sinais foi apenas o primeiro passo, mas ainda compreendia-se como necessário a disseminação da Libras para que as pessoas surdas tivessem acessibilidade linguística nos diversos meios da sociedade. A mesma lei que oficializou a língua de sinais já previa essa difusão:

Deve ser garantido, por parte do poder público em geral e empresas concessionárias de serviços públicos, formas institucionalizadas de apoiar o uso e difusão da Língua Brasileira de Sinais - Libras como meio de comunicação objetiva e de utilização corrente das comunidades surdas do Brasil (BRASIL, 2002).

Pautadas no excerto supracitado, compreendemos que o objetivo desta lei é tornar a língua de sinais conhecida em todo território nacional para que pessoas ouvintes tenham contato com a Libras a fim de oferecer amparo quanto à comunicação entre surdos e ouvintes. Porém, apesar de a lei apresentar essa 
necessidade, foi percebido que pouco se falava na língua de sinais, e, consequentemente, os surdos continuavam com barreiras na interação com a sociedade por falta de profissionais capacitados para realizar a tradução da Libras para a língua portuguesa e vice-versa. Esses profissionais a quem nos referimos tratam-se dos intérpretes de língua de sinais que atuam como mediadores nas interações linguísticas das pessoas surdas com a sociedade em geral. No ano de 2005, foi aprovado o decreto $n^{\circ} 5.626 / 2005$ que veio regulamentar a lei $n^{\circ}$ 10.436/2002 e o artigo 18 da Lei 10.098/00 e ampliar as possibilidades de inserção da pessoa surda ao meio.

O referido decreto trata da inclusão da Libras como disciplina curricular nos cursos de Licenciatura e Fonoaudiologia, bem como dispõe sobre a formação do professor e instrutor de língua de sinais e da formação do profissional intérprete. Além disso, no artigo 14 do capítulo IV do Decreto 5.626/2005, encontramos a seguinte redação:

As instituições federais de ensino devem garantir, obrigatoriamente, às pessoas surdas acesso à comunicação, à informação e à educação nos processos seletivos, nas atividades e nos conteúdos curriculares desenvolvidos em todos os níveis, etapas e modalidades de educação, desde a educação infantil até à superior (BRASIL, 2005).

É pela real implementação deste artigo que a comunidade surda no Brasil tem levantado debates e buscado esforços para que as garantias nele previstas de fato vigorem, pois segundo Monteiro (2006, p. 301), "o que os surdos temem é que, na pior das hipóteses, tudo continue como estava". Não basta que a língua seja reconhecida, é preciso oferecer meios para que as pessoas surdas sejam integradas nos diversos segmentos da sociedade.

Como o foco deste trabalho está direcionado à inclusão e à acessibilidade em ambiente educacional, destacamos o capítulo $\mathrm{V}$ do decreto que entende a necessidade do sujeito surdo de receber o acompanhamento do intérprete de Libras durante a realização de suas atividades acadêmicas: 
[...] as instituições federais de ensino da educação básica e da educação superior devem incluir, em seus quadros, em todos os níveis, etapas e modalidades, o tradutor e intérprete de Libras - Língua Portuguesa, para viabilizar o acesso à comunicação, à informação e à educação de alunos surdos (BRASIL, 2005).

Dessa forma, é garantindo a ele a possibilidade de intermediação na comunicação através do intérprete que, segundo Schubert (2012), não faz do surdo alguém menos capaz que os ouvintes. É preciso considerar que o fato de não ouvir deve ser entendido, no âmbito educacional, como diferença cultural e identitária e as mediações devem ocorrer de acordo com as necessidades linguísticas que se apresentam.

Compreendemos, então, que, atualmente, a grande luta da comunidade surda está voltada para a implementação das políticas públicas que a ela são garantidas por meio da legislação que abrange o direito à acessibilidade e à real inclusão na sociedade por meio da presença do intérprete de Libras nos espaços públicos como: bancos, aeroportos, rodoviárias, hospitais, escolas, universidades, dentre outros.

\section{A inserção do docente surdo no meio acadêmico e a importância do profissional intérprete como meio de acessibilidade}

Com a vigência do Decreto $n^{\circ} 5.626 / 2005$, o qual torna a disciplina de Libras obrigatória nos cursos de Licenciatura e formação de fonoaudiólogos, houve um grande avanço na profissionalização do surdo, uma vez que, por meio desse decreto, o sujeito surdo se viu motivado a estudar e alcançar a formação exigida para assumir o papel de educador, já que o objeto da disciplina é sua própria língua. Porém, com a entrada do professor surdo na docência, na Educação Básica e no Ensino Superior, é necessário pensar como a escola e a Universidade têm se organizado para receber esse profissional, de modo a garantir-lhe uma ampla e verdadeira inclusão.

Dentre as medidas que podem ser tomadas para efetivar a inclusão do surdo na sociedade se destaca a contratação de intérpretes de língua de sinais, que se 
configuram como mediadores nas interações linguísticas entre surdos e ouvintes. Rodrigues, Oliveira e Silva (2019) pontuam que o profissional intérprete "carrega em sua bagagem curricular conhecimentos teóricos e práticos que proporcionarão a facilitação de um intercambio no processo da aprendizagem" (RODRIGUES; OLIVEIRA; SILVA, 2019, p. 98).

Assim, é por meio destes profissionais que os surdos têm sua acessibilidade linguística garantida no ambiente educacional. Tal fato, para Schubert (2015), faz com que esse ambiente seja, de fato, inclusivo. De acordo com Abreu (2006), o intérprete da Língua Brasileira de Sinais é aquele que, tomando a posição do sinalizador ou do falante, transmite os pensamentos, palavras e emoções do sinalizador/comunicador/falante, servindo de elo entre duas modalidades de comunicação.

O intérprete, apesar de estar presente desde muito tempo nas interações dos surdos com a comunidade de ouvintes, só teve sua profissão reconhecida oficialmente por meio da Lei no 12.319 no ano de 2010. Segundo a referida lei, "o tradutor e intérprete terá competência para realizar interpretação das duas línguas de maneira simultânea ou consecutiva e proficiência em tradução e interpretação da Libras e da Língua Portuguesa" (BRASIL, 2010).

Para ressaltar a importância do intérprete no convívio social do surdo, especificamente no ambiente educacional, convém citar Schubert (2012), quando afirma que na ausência de um intérprete, o surdo corre o risco de ficar alienado, sem a possiblidade de interagir, questionar, levantar críticas e dúvidas, ficando sempre em uma situação passiva. Nesse sentido, o intérprete assume o papel de interlocutor na comunicação entre alunos ouvintes e professor surdo, garantindo, então, a possibilidade do diálogo entre os pares, evitando que, na verdade, ocorra uma espécie de nulidade comunicativa no ambiente de docência. Ressaltamos que nosso foco de investigação é a promoção da acessibilidade linguística ao docente surdo em instituições de ensino superior, em especial na UFG/Regional Catalão.

Compreendemos, assim, que o fato de o profissional surdo ser admitido para compor o quadro de docentes de uma instituição de ensino superior não significa 
que ele esteja verdadeiramente incluído neste ambiente. Fazer parte da comunidade acadêmica não significa estar incluso nessa comunidade. É sabido que a interação entre as pessoas acontece, principalmente, por meio da comunicação, em que os pares expressam ideias, fazem questionamentos, e, sobretudo, compartilham experiências. Diante disso, precisamos pensar na situação do docente surdo quando simplesmente está privado de estabelecer uma comunicação efetiva com as pessoas que compõem seu ambiente de trabalho e até mesmo com seus alunos.

Por isso, a presença do profissional intérprete nas universidades onde há professor surdo é vista não somente pela pessoa surda, mas também pelos demais docentes e funcionários da instituição, como indispensável para que haja uma socialização e convivência entre si. Contudo, sem a presença de um profissional capacitado para fazer a interpretação das duas línguas e, consequentemente, possibilitar a interação comunicativa entre as pessoas ouvintes e professor surdo, não são raras as situações de constrangimento de ambas as partes na tentativa de estabelecer comunicação.

Portanto, apesar de a inserção do professor universitário surdo ter se tornado recorrente na atualidade, percebemos que ainda são poucas as pesquisas que contemplam a realidade vivenciada pelo docente surdo no tangente à sua interação comunicativa com as demais pessoas ouvintes que fazem parte do seu meio. As pesquisas, e até mesmo as leis que tratam da inclusão da pessoa surda no ambiente escolar, estão mais voltadas ao aluno, tornando, assim, rara a aparição do professor surdo nas discussões acerca de inclusão e acessibilidade. Por isso, essa pesquisa visa a direcionar um olhar atento às necessidades do educador surdo, bem como as medidas de acessibilidade que vêm sendo implementadas pelas instituições, a fim de incluí-lo em seu ambiente de trabalho, tendo em vista que esse profissional se constitui como um sujeito que necessita de acessibilidade tanto quanto o educando surdo. 


\section{A acessibilidade aos docentes surdos da UFG/RC}

Conforme citado na seção 1 deste artigo, com a vigência do decreto legislativo $n^{\circ} 5.626 / 2005$, a disciplina de Libras se tornou obrigatória nos cursos de Licenciatura e Fonoaudiologia. Em decorrência disso, no mesmo decreto fica instituído que as pessoas surdas terão preferência no ensino da Libras, uma vez que, por meio delas, os alunos poderão compreender de maneira mais significativa aspectos sobre a língua e a cultura surda. Portanto, é nessa prerrogativa conferida ao surdo que ele enxerga uma oportunidade de se profissionalizar para assumir o papel de educador no ensino superior.

Não diferente das demais instituições de ensino superior, a Universidade Federal de Goiás/Regional Catalão (UFG/RC) também admitiu esse profissional em seu quadro de funcionários. Por isso, procuramos informações detalhadas sobre a presença de educadores surdos que atuaram/atuam na UFG/RC com o objetivo de analisar se estiveram/estão realmente inseridos na instituição e se tem sido proporcionado a eles um ambiente acessível.

Solicitamos, via memorando ao Departamento Pessoal (DP) da referida universidade, as seguintes informações: trabalha ou trabalhou algum docente surdo na Regional? Quantos já foram admitidos até a data atual? Qual o tipo de contrato destes educadores? Quando iniciaram seus trabalhos? Em qual unidade acadêmica estavam/estão lotados? Durante o exercício da função destes profissionais, houve a contratação do intérprete de Libras? Tendo essa solicitação plenamente atendida pelo DP da UFG/RC, buscamos correlacionar as respostas recebidas com a conduta da UFG/RC no que tange às medidas de acessibilidade por ela adotadas. Feita essa relação, buscamos a legislação que abrange a área da acessibilidade e inclusão da pessoa surda que nos serviu de suporte para uma análise da situação do docente surdo na Regional Catalão.

De acordo com o memorando $\mathrm{n}^{\circ} 013$ expedido pelo DP, nos inteiramos de que no ano de 2010, a UFG/RC lançou um edital para a contratação de um professor substituto para ministrar aulas de Libras nos cursos de Licenciatura 
conforme as exigências do decreto 5.626/2005. E foi por meio desse edital que chegou à UFG/RC o primeiro professor surdo, doravante P1.

A contratação deste profissional ocorreu no dia 31/03/2010 e, por se tratar de um contrato temporário, a data estabelecida para o seu término foi o dia 31/12/2011. Entretanto, antes mesmo do término do contrato do $\mathrm{P} 1$, devido à grande demanda por professores de Libras, foi necessário disponibilizar vaga para um segundo docente que ministrasse aulas da disciplina. Sendo essa vaga também preenchida por um professor surdo que aqui denominaremos de P2. Assim como o P1, o P2 também trabalhou na condição de professor substituto, tendo seu contrato estabelecido do dia 31/03/2011 ao dia 31/12/2011.

No ano seguinte, no mês de julho, o P1 foi novamente contratado como professor substituto de Libras, através de um contrato firmado com a Prefeitura Municipal de Catalão. A vigência do contrato foi de 02/07/2012 até 30/06/2013. Findando o segundo contrato, o P1 foi contratado pela terceira vez no ano de 2014, para atuar como professor substituto da mesma disciplina. O P1 exerceu sua função na universidade no período de 01/01/2014 até 10/06/2014. E, novamente, enquanto vigorava o contrato do P1, o P2 foi, pela segunda vez, admitido como docente substituto na UFG/RC, tendo o seu contrato firmado no dia 14/03/2014, estando em execução até a atualidade.

Ao questionamento acerca da contratação do profissional intérprete, recebemos como resposta por parte do DP, a informação de que não houve a contratação de intérprete nesse período. Notamos, que apesar da legislação vigente, a UFG/RC, por motivos que não nos foram informados, não cumpriu o previsto no decreto $n^{\circ} 5.626 / 2005$, no qual se pontua que:

[...] as instituições federais de ensino da educação básica e da educação superior devem incluir, em seus quadros, em todos os níveis, etapas e modalidades, o tradutor e intérprete de Libras - Língua Portuguesa, para viabilizar o acesso à comunicação, à informação e à educação de alunos surdos (BRASIL, 2005).

Ainda ponderando sobre a importância do intérprete no contexto acadêmico, tomaremos o relato de uma professora surda quando afirma que "[...] a presença do 
intérprete possibilitava a participação, em igualdade, dos surdos e dos ouvintes [...]". (ALMEIDA, 2010 p. 32).

Não obstante às exigências do decreto, mesmo sem a implementação das medidas de acessibilidade aos docentes surdos contratados como substitutos, em 2014 a situação na UFG/RC se alterou significativamente pois o terceiro professor surdo chega à Universidade, porém, na qualidade de professor efetivo, após ser aprovado no concurso para professor de Libras, pela Unidade Acadêmica Especial de Letras e Linguística (UAELL) da referida Regional. O P3, como o denominaremos doravante, iniciou suas atividades no dia 10/07/2014.

Com a presença do docente efetivo, a Universidade se viu, de certa forma, pressionada a oferecer a esse profissional o acompanhamento do intérprete de Libras. Porém, sob a alegação de que a instituição não dispunha de recursos financeiros para realizar a contratação de um profissional devidamente capacitado, foi viabilizado por meio da UAELL, unidade ao qual o docente estava lotado, o contrato de uma aluna que tinha conhecimento da língua de sinais para atuar como bolsista, desenvolvendo a função de intérprete do P3, acompanhando-o nas reuniões da unidade e nos demais eventos a que o professor comparecesse. $E$ foi apenas com a entrada do P3, na qualidade de aluno, no Programa de Mestrado em Estudos da Linguagem, vinculado à UAELL da universidade, que ocorreu a contratação oficial de um intérprete para acompanhá-lo em suas atividades enquanto discente. Pontuamos que essa foi uma iniciativa da Coordenadoria do Programa de Mestrado, em ação conjunta com a Coordenação de Pesquisa e Pós-graduação da UFG/RC.

Além disso, no memorando que recebemos do DP, nos é informado que no mês de março de 2015, oito meses após a entrada do professor surdo efetivo na Regional, foi lançado edital de concurso público para a admissão de novos técnicos administrativos com vagas para diversas áreas de formação distribuídas entre todos os Campi e Regionais da universidade Federal de Goiás. Dentre elas, foi disponibilizada uma vaga para Tradutor Intérprete de Língua de Sinais (TILS) com lotação na cidade de Catalão para atender à demanda da Regional. Ainda de acordo 
com o memorando, a previsão de posse do candidato aprovado no concurso seria para dezembro de 2015, o que realmente ocorreu.

Não podemos deixar de problematizar o fato de a Universidade se organizar de maneira diferente com a chegada do professor efetivo, pois não deveria anular a necessidade dos demais professores que se fizeram/ fazem presentes na instituição na condição de substitutos.

Percebemos, então, que, aparentemente, a Universidade se mostra inclusiva quando tem em seu quadro de funcionários pessoas com deficiência. Para quem faz uma leitura superficial do ambiente, acredita que realmente trata-se de um espaço inclusivo que oferece oportunidade às pessoas no mercado de trabalho. Mas com um olhar mais atento, percebemos que há uma falha nesse processo de inclusão profissional e essa falha diz respeito ao fato de não estar sendo oferecido o que a comunidade surda tanto lutou para alcançar: o direito à comunicação e interação com a sociedade, também aos professores substitutos uma vez o P2 não é assistido pelo intérprete, salvo se compartilhar situações com o P3, como reuniões departamentais. O intérprete, na UFG/RC, assim, passa a ter função personalizada para assistir exclusivamente ao professor efetivo.

Pensando sobre a admissão do docente surdo e sua participação ativa nas atividades acadêmicas a ele atribuídas, nos inquieta o fato de a pessoa surda ter como primeira língua $\left(\mathrm{L}^{2}{ }^{2}\right)$ a Libras, isso significa que ele não faz uso da mesma modalidade linguística que os demais integrantes de seu local de trabalho, logo, ele necessita de estratégias que visem a sua integração e socialização no ambiente do qual faz parte.

Ainda ponderando sobre o ambiente inclusivo, apresentaremos $\mathrm{e}$, posteriormente, discutiremos as medidas tomadas pela Universidade a fim de oferecer acessibilidade aos profissionais surdos. Nesse mesmo sentido, as disposições finais do decreto $n^{\circ} 5.626 / 2005$, deixam claro que:

Os órgãos da administração pública federal, direta e indireta, devem incluir em seus orçamentos anuais e plurianuais dotações destinadas a viabilizar ações previstas neste Decreto, prioritariamente as

\footnotetext{
${ }^{2} \mathrm{O}$ P3 é fluente em língua portuguesa e demonstra suficiência em língua inglesa, em interações no
} cotidiano da UFG/RC e redes sociais. Já o P2 tem a Libras como segunda língua. 
relativas à formação, capacitação e qualificação de professores, servidores e empregados para o uso e difusão da Libras e à realização da tradução e interpretação de Libras - Língua Portuguesa [...] (BRASIL, 2005).

Para tomarmos conhecimento acerca da difusão da língua de sinais na universidade, entramos em contato por meio de um memorando enviado ao Departamento de Desenvolvimento em Recursos Humanos (DDRH) da Regional Catalão para a obtenção das informações pertinentes. Recebemos resposta também por meio de um memorando, sendo ele o de $n^{\circ} 10 / 2015$ pelo qual tomamos conhecimento da promoção de um curso de Libras ofertado aos servidores da UFG/RC, como técnicos administrativos e docentes, bem como aos profissionais terceirizados, bolsistas e estagiários com vínculo com a UFG/RC. De acordo com o memorando, o curso foi uma iniciativa do próprio DDRH, que objetivou apresentar questões comuns referente aos surdos e sua organização social e cultural por meio da aprendizagem da língua de sinais. O curso ocorreu no período de 26/03/2014 a 29/10/2014, sendo executado em três horas semanais e somando a carga horária total de 92 horas. Ao todo, foram oferecidas 20 vagas.

Apesar de o número de vagas parecer insuficiente, se comparado à amplitude do público alvo, apenas dezoito pessoas se inscreveram no curso e nove o concluíram. Esse dado é extremamente preocupante visto que a comunidade acadêmica da UFG/RC convive com pessoas surdas desde a entrada do primeiro docente surdo que ocorreu no ano de 2010. Notamos que, ainda que tardia, a atitude dos gestores de disseminar a língua de sinais não despertou o interesse dos funcionários da instituição. A carga horária total do curso também é um agravante, visto que é inviável o aprendizado de uma segunda língua em apenas 92 horas, especialmente se consideramos que é um outro código e outro canal acarretando, sobretudo, uma outra estrutura gramatical, posto que não há correspondência icônica entre L1 e Libras

Apesar de fazermos algumas ressalvas quanto ao curso, não podemos desconsiderar a importante iniciativa tomada por parte da Universidade em cumprimento ao Decreto $n^{\circ} 5.625 / 2005$ que estabelece o apoio e difusão da Libras 
dentro da comunidade escolar que contemple, professores, alunos e funcionários. Desse modo, o objetivo foi amenizar as dificuldades de comunicação das pessoas surdas. Entretanto, por outro lado, notamos o desinteresse dos servidores em criar um ambiente inclusivo com pessoas preparadas para compreender e lidar com as pessoas surdas. É por isso que, nos dias de hoje, o processo de inclusão do surdo tem constantemente esbarrado na falta de comunicação.

Ao passo que o tema acessibilidade foi se tornando recorrente na sociedade, e, sobretudo, no ambiente acadêmico, foi necessário que a Universidade Federal de Goiás começasse a pensar sobre como contribuir para o processo de inclusão das pessoas com deficiência na esfera acadêmica. A partir dessas reflexões, a UFG instituiu a criação de Núcleos de Acessibilidade (NA) em todas as Regionais. Conforme o artigo publicado no Jornal UFG em março de 2015, o Núcleo de Acessibilidade é uma estrutura administrada que promove a organização de ações institucionais, visando a garantir a inclusão e a permanência de pessoas com deficiência na vida acadêmica. Dentre as ações que devem ser promovidas pelo NA, estão o combate ao preconceito, a garantia do direito de ir e vir, bem como a disponibilidade de meios para o sucesso acadêmico (LIMA, 2015).

$\mathrm{Na}$ Regional Catalão, as discussões sobre a criação do NA iniciaram em abril de 2015, e desde então têm ganhado forças junto à direção da universidade no sentido de promover a inclusão e acessibilidade para os alunos, professores e funcionários que se enquadram como público alvo da educação especial. No que diz respeito à contratação de intérpretes de Libras, o Núcleo de Acessibilidade viabilizou no ano de 2017 a contratação de mais um servidor efetivo, totalizando dois intérpretes na instituição. Acreditamos, que com a efetivação das propostas do NA, a Universidade Federal de Goiás / Regional Catalão tem atribuído aos profissionais surdos um olhar mais atento a fim de que seus direitos sejam assegurados e cumpridos.

\section{Considerações finais}


Essa pesquisa apresentou e discutiu políticas públicas voltadas à acessibilidade dos professores universitários surdos, bem como o posicionamento da UFG/RC frente aos desafios da sua implementação.

Mediante o exposto, pudemos, por meio da análise da documentação e da legislação, constatar barreiras na acessibilidade e na inclusão desses docentes no contexto profissional em que estão inseridos, neste caso, na UFG/ RC. Isso ocorre porque a Libras não é utilizada pelos demais indivíduos da comunidade acadêmica e tampouco foi disponibilizado intérprete de língua de sinais para os substitutos e o efetivo foi assistido pelo intérprete quando ele se tornou aluno de programa de pós-graduação. Tais constatações nos levam a questionar o modo como a palavra inclusão tem sido compreendida pela sociedade. Ponderamos que incluir não significa admitir apenas. É necessário tornar o espaço inclusivo. É papel da universidade oferecer amparo a esses profissionais quanto à eliminação das barreiras de comunicação com o grupo acadêmico em geral.

Conforme discutimos na Introdução, atualmente, a luta da comunidade surda está voltada para o cumprimento do Decreto $n^{\circ} 5.626 / 2005$, que dispõe, dentre outros assuntos, a obrigatoriedade do intérprete de libras nos espaços públicos. Compreendemos, então, a importância desse profissional, que se configura como mediador nas interações linguísticas entre surdos e ouvintes. É por meio deste profissional que os surdos têm sua acessibilidade linguística garantida, também no ambiente educacional.

Essa pesquisa veio possibilitar o direcionamento do foco para o educador surdo. Nosso objetivo foi mostrá-lo como um sujeito que necessita de acessibilidade tanto quanto o aluno surdo. Durante o processo de pesquisa e análise, percebemos que ainda são poucos os questionamentos voltados à acessibilidade desse profissional. Há falhas até mesmo na legislação que trata deste tema, pois o mais encontrado é o termo aluno surdo, quando o ideal seria sujeito surdo.

Contudo, faz-se necessário que a Universidade repense sobre as diferenças linguísticas existentes dentro do contexto, para que efetive os direitos de forma 
<https://periodicos.ufpel.edu.br/ojs2/index.php/caduc/article/view/1603/1486>. Acesso em: 23 dez. 2015.

Recebido em: 14/07/2018

Aprovado em: 04/07/2020 